\title{
A wider view on gastric erosion: detailed evaluation of complex somatic and behavioral changes in rats treated with indomethacin at gastric ulcerogenic dose
}

\author{
${ }^{1}$ Filaretova LP, ${ }^{1}$ Bagaeva TR, ${ }^{1}$ Morozova OY, ${ }^{2}$ Zelena D \\ ${ }^{1}$ Laboratory of Experimental Endocrinology, Pavlov Institute of Physiology, St. Petersburg, Russia; ${ }^{2}$ Institute of \\ Experimental Medicine, Budapest, Hungary \\ E-mail: filaretovalp@yandex.ru
}

Objective. Gastric erosion is widespread side effect of nonsteroidal anti-inflammatory drugs. To examine the complexity of the brain-gut axis regulation, indomethacin-induced gastric erosion formation was studied in connection with somatic and behavioral changes.

Methods. During a constant telemetric recording of heart rate, body temperature, and locomotion of male rats we examined the effects of $24 \mathrm{~h}$ fasting, indomethacin $(35 \mathrm{mg} / \mathrm{kg} \mathrm{s.c.})$ injection, and refeeding at $4 \mathrm{~h}$. Behavior was analyzed on elevated plus maze (EPM) at $24 \mathrm{~h}$ and somatic changes at $72 \mathrm{~h}$.

Results. Gastric erosion developed $4 \mathrm{~h}$ after indomethacin injection, healed $72 \mathrm{~h}$ later contrasted by large injury in the small intestine. As classical signs of chronic stress, body and thymus weight were reduced while adrenal weight was enhanced $72 \mathrm{~h}$ after indomethacin injection. Fasting by itself changed all telemetrically recorded parameters with most prominent decrease in heart rate. Indomethacin induced similar diminishing effects with earliest and strongest temperature decrease. As a sign of more anxious phenotype locomotion reducing effect of indomethacin injection was detected on EPM. The EPM-induced temperature elevation was missing in indomethacin-treated animals.

Conclusions. Fasting by itself induce somatic changes, which can make the animals more vulnerable to ulcerogenic stimuli. Development of indomethacin-induced gastrointestinal lesions happened in parallel with disturbances of heart rate, core body temperature, and chronic stress-like somatic changes as well as anxiety-like behavior. We have to be more aware of the existence of the brain-gut axis and should study changes in the whole body rather than focusing on a specific organ.

Key words: indomethacin, gastrointestinal injury, telemetry, heart rate, body temperature, locomotion, somatic parameters, elevated plus maze.

In our aging society the prevalence of locomotor disorders are increasing. An account of their analgesic and anti-inflammatory effects nonsteroidal antiinflammatory drugs (NSAIDs) would be one of the best choices for their treatment (Laine 2002). The main factor limiting use of NSAIDs is concern about their gastrointestinal (GI) side effects (Hawkey 2000; Wallace and Vong 2008). Their use is associated with a significant risk of GI bleeding, ulcer perforation, and symptomatic peptic ulcer disease. Approximately 1-2\% of NSAID users develop upper GI complications per year, a rate 3-5 times higher than in non-NSAID users (Targownik et al. 2008). Experimental studies with NSAIDs confirm the clinical data that NSAIDs cause damage to the up-

Corresponding author: Ludmila Filaretova, PhD, DSci.; Laboratory of Experimental Endocrinology, Pavlov Institute of Physiology, Russian Academy of Sciences, Makarova 6, St. Petersburg 199034, Russia; phone: +7(813)70-72-771; fax: +7(812)328-05-01; e-mail: filaretovalp@yandex.ru. 
per GI tract and also affect the lower GI tract (Sostres et al. 2013).

Indomethacin (IM) which is the most widely studied of the NSAID medications was introduced in 1963 for the treatment of rheumatoid arthritis and related diseases. A reduction in the biosynthesis of prostaglandin through inhibition of cyclooxygenase is the pharmacological background to both the anti-inflammatory action (Vane 1971) and the harmful side effects of IM as well as other NSAIDs (Hawkey 2000). IM is widely used ulcerogenic stimulus in experimental studies (Filaretova 2013; Filaretova et al. 2013).

Effects of ulcerogenic stimuli on the GI tract, including stress and IM, depend on the general conditions of the body as well as on the situation in which the person or animal is. Firstly, in critically ill patients the health risk of gastric ulceration is about $100 \%$ (Laine et al. 2008). Secondly, gastroprotective effect of preconditioning stress (Filaretova et al. 2008) confirms that gastric ulceration depends on the situation in which animal is. Moreover, it is also widely known, that personality (Magni et al. 1988; Juby and Davis 1991) and psychological factors (Magni et al. 1986) like high level of anxiety strongly influence the vulnerability, i.e. the occurrence and severity of gastric ulcerations (Overmier and Murison 2000). In the last few years more emphasize was given to the existence of the brain-gut axis, thus it became clear that the process goes both directions, i.e. the stage of the GI tract strongly influences our higher brain functions. This aspect has been investigated to a lesser degree. This explains why our interest was focused on the general changes in the body during IM-induced gastric ulceration. Many authors deal with the effect of intestinal microbiome on the general well-being (e.g. Foster and McVey Neufeld 2013; Farmer et al. 2014; Tillisch 2014), which can be transmitted through neural (nervus vagus) (Klarer et al. 2014), hormonal, immune, and metabolic pathways (Borre et al. 2014). It was already confirmed that IM treatment induce remarkable changes in microbiome (Imaeda et al. 2012; Teran-Ventura et al. 2014) and vagal nerve function interacts with its effect (Karadi et al. 2001). Thus, we might assume that beside somatic changes, IM-induced ulceration will be accompanied by enhanced anxiety-like symptoms.

In animal models reproducible gastric ulceration is induced in fasted animals. Gastric mucosa of fasted animal is more susceptible to ulcerogenic stimuli for several, local reasons, including an absence of protective role of chimus and deficiency of glycoproteins in mucus
(Dekanski et al. 1975). On the other hand, fasting may induce general changes in the body, which makes it more vulnerable to ulcerogenic stimuli. This later hypothesis requires experimental evidence.

Here we aimed to examine the complex regulation of the brain-gut axis after IM treatment. Therefore IMinduced gastric erosion formation was studied in connection with somatic and behavioral changes.

\section{Materials and Methods}

Animals. Subjects were 2-3 month old male rats (Wistar for Exp. 1; Charles River Laboratories, Hungary and Sprague Dawley for Exp. 2; Russia) weighting 250-300 g at the start of the experiments. Food and water were available ad libitum, while temperature and relative humidity were kept at $21 \pm 2^{\circ} \mathrm{C}$ and $60 \pm$ $10 \%$, respectively. Rats were kept under $12 \mathrm{~h}$ cycle with lights on at 22:00 h (Exp. 1) or at 7:00 h (Exp. 2). For better evaluation of behavior the animals were kept in reversed cycle in Exp.1. Acclimatization to the reversed cycle lasted for 2 weeks. It raises the question if there is a difference between the effect of IM injection at the beginning of the light (more general) or dark phase. This question was tested during Exp. 2. As biotelemetry required individual housing initially group housed rats were single housed after surgery (Exp. 1) or 5 days prior to the start of the experiment (Exp. 2). Animals were naive to experimentation. Experiments were carried out in accordance with the European Communities Council Directive recommendations for the care and use of laboratory animals (2010/63/EU).

\section{Experiment 1.}

Telemetric recording. We implanted VitalView biotelemetry emitters (Minimitter Co. Bend, OR, USA) into the rats. The emitter was placed into the abdominal cavity through a midline abdominal incision under ketaminxylazine-pipolphen anesthesia (50-10-5 mg/kg in a volume of $2 \mathrm{ml} / \mathrm{kg}$ intraperitoneal, i.p.). The negative and positive heart rate leads were attached to the anterior right side of the chest (near the clavicle) and to the posterior chest wall (left to the sternum and anterior to the last rib), respectively. Biotelemetric recordings were made by means of a 12-channel VitalView system (Minimitter Co.). Data was taken once every minute around the clock and later summarized as an average (heart rate and temperature) or sum (locomotion) of 1 h or $10 \mathrm{~min}$. Circadian changes were calculated by subtracting the average of the values during light phase from the dark phase (Filaretova et al. 2011). 
Induction of gastric erosion. After 5 days recovery the animals were fasted for $24 \mathrm{~h}$ in an empty cage then IM was injected subcutaneously (s.c.) at ulcerogenic dose $(35 \mathrm{mg} / \mathrm{kg})$ at the beginning of the dark phase. Four hours after the IM or vehicle (saline with few drops of Tween 80) administration some animals $(n=8)$ were examined for the development of gastric erosion in our experimental conditions (the stress of operation is a preconditioning stimulus, which can profoundly influence the development of gastric erosion (Filaretova et al. 2008)). The majority of the animals ( $n=14$ Control and $\mathrm{n}=14$ IM-treated) were refed $4 \mathrm{~h}$ after the injection and the experiment was continued for another 3 days. Recording started 2 days before fasting and lasted $24 \mathrm{~h}$ after IM injection. During all these periods the heart rate, core body temperature, and locomotion were recorded automatically.

Elevated plus maze. Twenty-four hours after IM administration, the animals were tested on an elevated plus maze (EPM) during the beginning of the dark phase under red light illumination. Each rat was brought in its home cage to the test room and immediately placed on the central arena of the EPM with the head facing a closed arm. EPM was made from wood, painted dark grey and elevated $80 \mathrm{~cm}$ above the floor (arm length, $50 \mathrm{~cm}$; arm width, $20 \mathrm{~cm}$; central platform, $20 \times 20 \mathrm{~cm}$; closed arm walls height, $30 \mathrm{~cm}$ ). Surface of maze was washed with water and dried prior next animal was tested. Test duration was $5 \mathrm{~min}$. Animal's behavior was recorded by camera fixed above the maze and analyzed by trained observer later on. Percentage of time spent in open arms and open/total (total:open plus closed) arm entries ratio (entry:three paws of animal in an arm) were calculated and used as measures of anxiety. Closed arm entries were considered as indicators of general locomotor activity. Next to basic parameters grooming (self-grooming with forepaws and scratching with hind legs) was also calculated (Mikics et al. 2005).

\section{Experiment 2.}

After 5 days of single housing the animals were treated as mentioned above (see Induction of gastric erosion) at the beginning of the light or dark phase of the day. After refeeding at $4 \mathrm{~h}$ the animals were monitored for 3 days. The body weight of the animals was monitored daily. At the termination of the experiment the gastric and the intestinal mucosa were examined and the intestinal length was measured. The area (in $\mathrm{mm}^{2}$ ) of the gastric and the small intestinal lesions was measured using computer program Image J, summed per animal, and used as a lesion score. Adrenal gland and thymus weights as well as plasma corticosterone level were also examined. Plasma corticosterone measurement was done by a spectrofluorimetric micromethod. For details see Filaretova et al. (1998). Intra- and interassay variations of measurements were $5.1 \%$ and $7.4 \%$, respectively.

Statistical analysis. Data are expressed as mean \pm SEM. Statistical significance was tested by repeated measure ANOVA (for telemetric data and body weight; factors treatment and time) or one (EPM; factor treatment) or two ways (morning-evening; factors treatment and day) ANOVA module of the StatSoft 11.0 (StatSoft, Inc., Tulsa, OK, USA) followed by Newman Keul's post hoc comparisons in the case of significant interactions. $\mathrm{p}<0.05$ was considered to be significant.

\section{Results}

\section{Experiment 1.}

Telemetric recordings. In this experiment we confirmed the development of gastric erosion $4 \mathrm{~h}$ after the IM treatment (erosion area: $19.84 \pm 6.4 \mathrm{~mm}^{2}$ ). At the termination of the experiment (in 3 days after IM injection) significantly smaller erosion $\left(8.8 \pm 1.8 \mathrm{~mm}^{2}\right)$ was still visible in the stomach with a concomitant severe intestinal damage (lesion area in the intestine: $444.6 \pm 181.9 \mathrm{~mm}^{2}$ ).

Twenty-four $\mathrm{h}$ fasting by itself induced remarkable changes in the telemetrically measured parameters (Fig. 1). Compared with the previous $24 \mathrm{~h}$ (Control, normally fed) of the same animals fasting induced a significant reduction in the heart rate (treatment: $\mathrm{F}(1,70)=15.6$, $\mathrm{p}<0.01$; Fig. 1A). This effect started already during the third hour of fasting and became more pronounced with time (treatment $\mathrm{x}$ time interaction: $\mathrm{F}(23,1610)=5.07, \mathrm{p}<0.01)$ despite the lower heart rate of the animals during the light phase of the circadian cycle (time: $\mathrm{F}(23,1610)=195.4, \mathrm{p}<0.01)$.

The body temperature changes were not that unambiguous. There was no overall effect of fasting on this parameter, but the decrease during the light phase (time: $\mathrm{F}(23,1610)=199.8, \mathrm{p}<0.01$; Fig. 1B) was more explicit in fasting rats (treatment $\mathrm{x}$ time interaction: $\mathrm{F}(23,1610)=10.9, \mathrm{p}<0.01)$. It seems that the circadian changes was more pronounced in fasted animals $(-1.07$ $\pm 0.04^{\circ} \mathrm{C}$ compared to $-0.70 \pm 0.04^{\circ} \mathrm{C} ; \mathrm{F}(1,70)=29.0$, $\mathrm{p}<0.01)$.

Locomotion of fasted animals were higher compared to normally fed rats (treatment: $\mathrm{F}(1,70)=5.5$, 

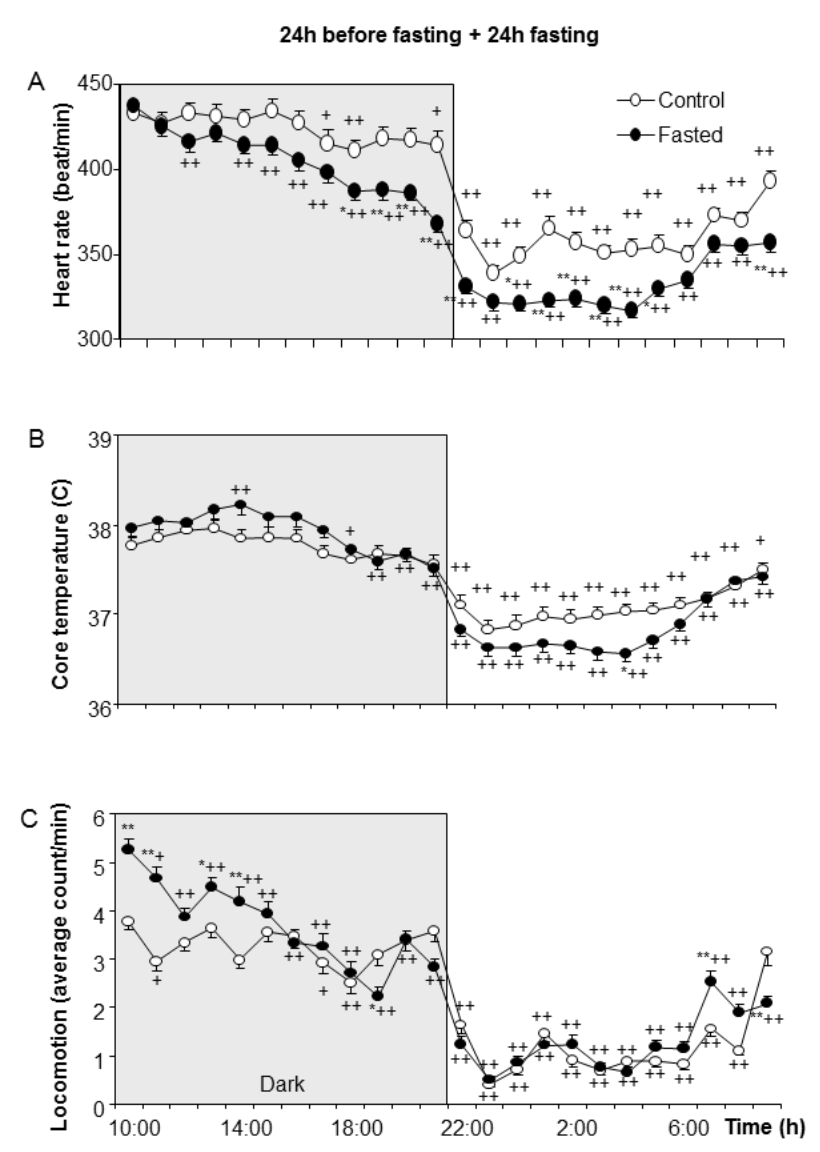

Fig. 1. Somatic changes induced by $24 \mathrm{~h}$ fasting. (A) Heart rate, $(B)$ core body temperature and $(\mathrm{C})$ locomotion were monitored by telemetric recordings. $n=36 ;{ }^{*} p<0.05,{ }^{* *} p<0.01$ vs. Control, normally fed (samples were taken from the same animals $24 \mathrm{~h}$ apart); $+\mathrm{p}<0.05,++\mathrm{p}<0.01$ vs. 10:00 $\mathrm{h}$.

p $<0.05$; Fig. 1C). This parameter also showed circadian variation with lower levels during the light phase (time: $\mathrm{F}(23,1610)=108.9, \mathrm{p}<0.01)$, which was influenced by fasting at certain time points only (treatment $\mathrm{x}$ time interaction: $\mathrm{F}(23,1610)=7.9, \mathrm{p}<0.01)$.

During the first $24 \mathrm{~h}$ after IM injection (during gastric ulceration and healing), significant changes were detectable in heart rate, core body temperature, and locomotion (Fig. 2). Both s.c. IM injection and refeeding induced significant and long-lasting (80-90 min) elevations in all three parameters.

In the case of heart rate, there was no overall treatment effect (Fig. 2A). More specifically, the differences between vehicle and IM-treated animals were not apparent during the development of gastric ulcer (first $4 \mathrm{~h}$ ) and started just approximately $3 \mathrm{~h}$ after refeeding. Moreover, the heart rate reducing effect of IM remained visible during the light phase with lower overall heart rate (time: $\mathrm{F}(143,2145)=15.7, \mathrm{p}<0.01$; treatment $\mathrm{x}$ time interaction: $\mathrm{F}(143,2145)=2.3, \mathrm{p}<0.01)$.

A slightly different pattern was recognized in the case of core body temperature (Fig. 2B). Here there was a general treatment effect $(\mathrm{F}(1,17)=5.18, \mathrm{p}<0.05)$ with lower levels in IM-treated rats. This effect started already approximately $100 \mathrm{~min}$ after IM injection and intensified with time with huge difference even during the light phase with overall lower levels (time: $\mathrm{F}(143,2431)=32.3, \mathrm{p}<0.01$; treatment $\mathrm{x}$ time interaction: $\mathrm{F}(143,2431)=3.5, \mathrm{p}<0.01)$.

Locomotion showed only circadian changes (time: $\mathrm{F}(23,598)=8.53, \mathrm{p}<0.01$; Fig. $2 \mathrm{C})$ without any effect of IM treatment.

Elevated plus maze. When we tested the anxiety-like behavior on the EPM the only significant difference was the reduced locomotion (measured by the frequency of closed arm entries) of IM-treated animals $24 \mathrm{~h}$ after ulcerogenic injection $(\mathrm{F}(1,26)=7.56, \mathrm{p}=0.01$; Fig. $3 \mathrm{C})$. Despite slightly higher open arm time (Fig.3A) and the locomotion independent anxiety measure open/ total arm entries (Fig. 3B) only time spend with grooming showed a tendency to be higher in IM-treated rats $(F(1,13)=3.59, p=0.08$; Fig. 3D).

The heart rate of IM-treated animals were lower $24 \mathrm{~h}$ after the injection (treatment: $F(1,17)=12.7, p<0.01$; Fig. 3E). Although EPM induced a significant elevation (time: $\mathrm{F}(12,2047)=9.5, \mathrm{p}<0.01)$, but this change was similar in vehicle vs. IM-treated groups (no interaction between treatment and time).

In the case of temperature, not only the IM effect was significant $(\mathrm{F}(1,18)=18.2, \mathrm{p}<0.01)$, but the EPMinduced elevation $(\mathrm{F}(12,216)=8.3, \mathrm{p}<0.01)$ was visible in vehicle-treated animals only (treatment $\mathrm{x}$ time interaction: $\mathrm{F}(12,216)=3.2, \mathrm{p}<0.01$; Fig. $3 \mathrm{~F})$.

In agreement with the reduced closed arm frequency, the IM-treated animals moved less (treatment: $\mathrm{F}(1,17)=12.7$, $\mathrm{p}<0.01$; Fig. 3G). The EPM-induced locomotion elevation (time: $\mathrm{F}(12,204)=9.5 ; \mathrm{p}<0.01$ ) was the same in vehicle- and IM-treated animals (no treatment $\mathrm{x}$ time interaction).

Experiment 2. Twenty-four h fasting reduced the body weight of the animals significantly (Fig. $4 \mathrm{~A}$, day 0 and day 1 ), which was normalized in vehicle-treated animals within 3 days (time: $\mathrm{F}(2,30)=220.9, \mathrm{p}<0.01$ ). IM treatment significantly reduced the body weight during the 3 days examination period $(\mathrm{F}(1,15)=17.8, \mathrm{p}<0.01)$. This effect was visible only at day 3 as all other measurement was practically before the injection (treatment $x$ time interac- 
tion: $\mathrm{F}(2,30)=290.7, \mathrm{p}<0.01)$. The effect of the day (e.g. morning or evening injection) had no influence at all, even any of its interactions were not significant.

The weight of the thymus was reduced $(\mathrm{F}(1,15)=126.5$, $\mathrm{p}<0.01$; Fig. 4B), while the weight of the adrenal gland was enhanced $(F(1,15)=42.9, p<0.01$; Fig. $4 C)$ by IM treatment, without any influence of the day (e.g. morning-evening). In accordance what is widely known in rodents, the corticosterone levels were higher during the evening than during the morning hours (Fig.4D). The IM injection induced opposite changes at the different time points (treatment $\mathrm{x}$ time interaction: $\mathrm{F}(1,15)=11.2$, $\mathrm{p}<0.01)$. Namely, injected and sampled during the morning hours the resting corticosterone levels were elevated 3 days after the IM-treatment, while in case the injection/sampling was done during the dark phase IM-treatment tended to reduce the levels.

Three days after IM injection, gastric erosion was still visible in the stomach of IM-treated, but not vehicle treated rats (treatment: $\mathrm{F}(1,15)=7.3, \mathrm{p}=0.01$; Fig.4E). At the same time intestinal lesions were much more pronounced (treatment: $F(1,15)=171.6, p<0.01$; Fig.4F) reflected by reduced length of the intestine as well (treatment: $F(1,15)=28.4, p<0.01$; Fig.4G). Although gastric erosion and intestinal length were not influenced by the day at all, but the area of intestinal lesions was significantly smaller in case the injection/sampling was done during the dark phase (day: $\mathrm{F}(1,15)=6.06, \mathrm{p}<0.05$; treatment $\mathrm{x}$ day interaction: $\mathrm{F}(1,15)=6.06, \mathrm{p}<0.05)$.

\section{Discussion}

According to the results obtained, fasting itself induced somatic changes. In both experiments (Exp. 1 and 2), we confirmed that IM ( $35 \mathrm{mg} / \mathrm{kg}$ s.c.) injected to preliminary fasted rats produced hemorrhagic gastric mucosal erosion that was visible $4 \mathrm{~h}$ after the injection and that significantly healed in 3 days. The healing of IM-induced gastric erosion was followed by severe injury to the small intestine. Parallel to development of IM-caused GI lesions significant changes of heart rate, core body temperature and chronic stress-like somatic changes as well as anxiety-like behavior became apparent. These results suggest that IM-induced gastric injury may occur in tandem with complex somatic and behavioral changes.

Treatment with IM and other nonselective NSAIDs is associated with a high prevalence of GI adverse effects (Bjarnason et al. 2007; Hunt and Yuan 2011). Beside most widely known adverse side effect in upper GI tract

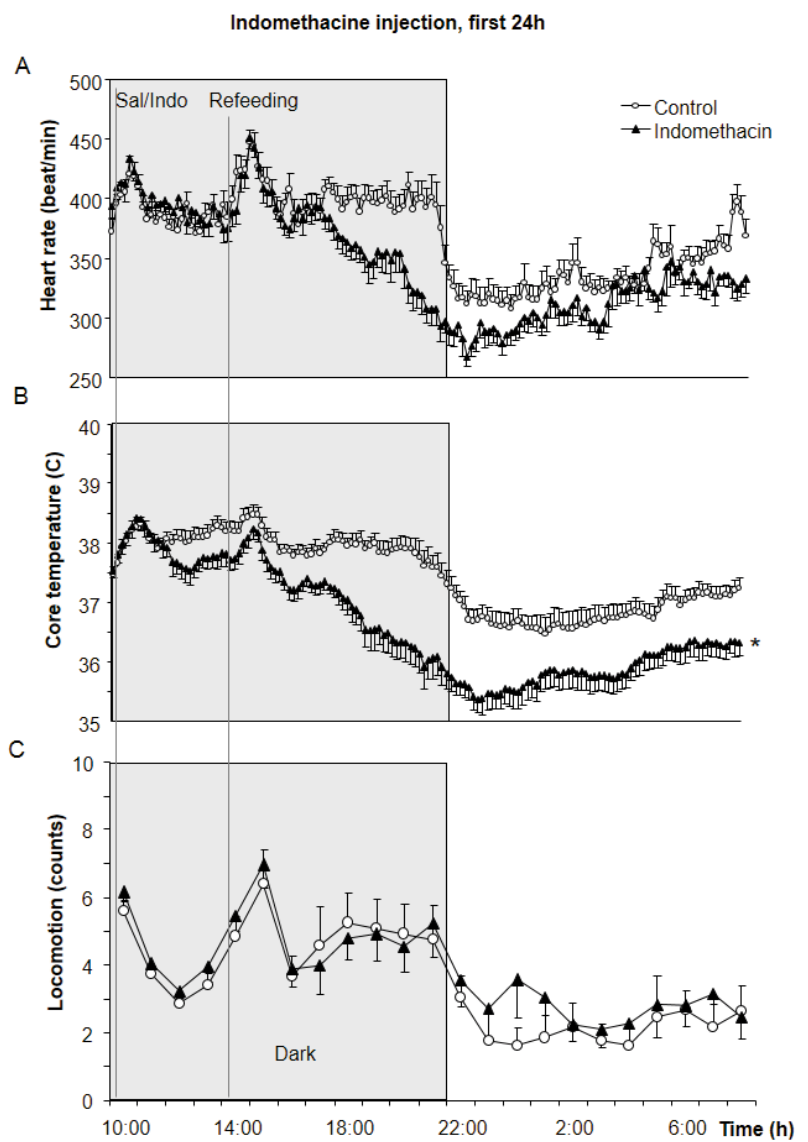

Fig. 2. Indomethacin-induced somatic changes. (A) Heart rate, $(B)$ core body temperature and $(\mathrm{C})$ locomotion were monitored by telemetric method during development and healing of gastric erosion induced by single indomethacin $(35 \mathrm{mg} / \mathrm{kg}, \mathrm{s.c}$.$) injection in fasted rats. Indomethacin treat-$ ment was followed by refeeding $4 \mathrm{~h}$ later. $n=14 ;{ }^{*} \mathrm{p}<0.05$ main treatment effect.

NSAIDs may also induced serious adverse effects in the small intestine as well as in cardiovascular system $(\mathrm{Ng}$ and Chan 2010). However, these side effects are investigated separately. Even the pathogenic mechanisms of NSAID-induced injury to the upper GI tract and the lower GI tract are still studied separately using different experimental models (Laine et al. 2008; Brzozowski 2010; Wallace 2011). To produce injury to the stomach, IM is usually injected to fasting rats or mice (Kato et al. 2009; Rios et al. 2010; Zelena and Filaretova 2010). On the contrary, for induction of injury to the small intestine IM is injected to fed animals (Kamei et al. 2008; Yoda et al. 2010; Kawahara et al. 2011). The results of the present and our previous (Filaretova et al. 2011) studies demon- 


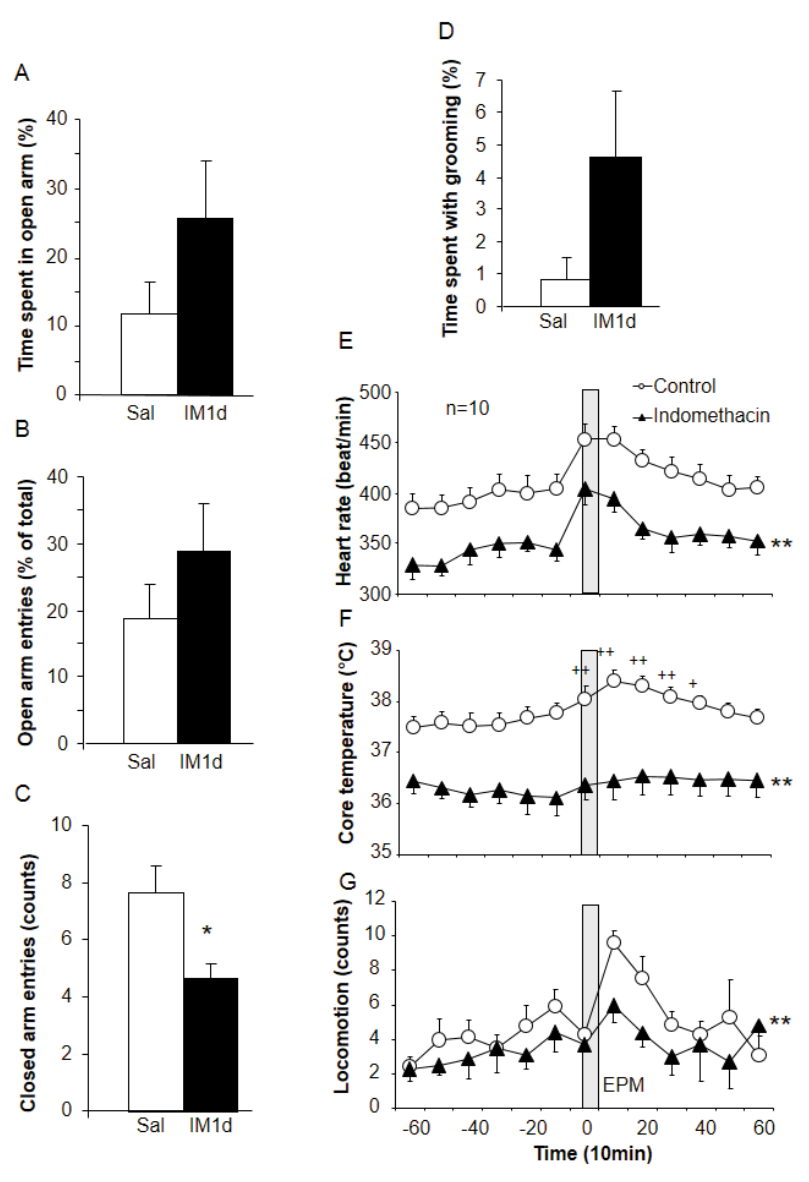

Fig. 3. Behavior on the elevated plus maze. The main anxiety measure, open arm time (A), as well as the locomotionindependent measure (Open arm entries (\% of total); (B) was not influenced significantly by IM treatment and refeeding $24 \mathrm{~h}$ before. There was a significant reduction of locomotion measured by both the closed arm entries $(\mathrm{C})$ and well as telemetric recordings $(G)$ in IM-treated rats. Both the heart rate (E) and core body temperature $(F)$ was reduced in IM-treated animals. The EPM-induced temperature elevation was not apparent in IM-treated rats. $n=14$; IM1 d: indomethacin treatment $\left(35 \mathrm{mg} / \mathrm{kg} \mathrm{sc}\right.$ in fasted rats) $24 \mathrm{~h}$ before ${ }^{\star} \mathrm{p}<0.05 \mathrm{vs}$. vehicle treated; ${ }^{* *} \mathbf{p}<0.01$ main treatment effect; $+\mathbf{p}<0.05 ;++p<0.01$ vs. $-60 \mathrm{~min}$ (initial).

strate that a single IM injection to fasting rats at gastric ulcerogenic dose may sequentially induce damage to the stomach and then, after refeeding, to the small intestine as well. It means that the enough fast healing of IM-induced gastric erosion (Filaretova et al. 2001; Filaretova et al. 2011) is not the end of pathological consequences of IM action. These findings suggest that new knowledge about mechanisms underlying NSAID-induced GI injury may come through integrative approach.
To continue our strategy of using integrative approach ( Filaretova et al. 2002; Filaretova et al. 2006; Filaretova et al. 2009; Filaretova 2011; Filaretova et al. 2014) and to understand what happens with the body as a whole ("in vivo"), in the present study we evaluated somatic and behavior changes in rats treated with IM at gastric ulcerogenic dose. Additionally to an appearance of severe injury to the small intestine, body and thymus weights were reduced while adrenal weight and the morning plasma corticosterone levels were enhanced 3 days after IM injection (Fig. 4). The long lasting increase in corticosterone levels together with the enlargement of the adrenal gland and the thymus involution confirmed a chronic activation of hypothalamic-pituitary-adrenocortical axis which could be a sign of inflammation. Indeed, besides injury to the small intestine as well as decrease in the intestinal length, a sign of hypermotility as a pathogenic element of inflammation (Filaretova et al. 2002), was detected in this part of GI tract (TeranVentura et al. 2014). It is worthy of note that the similar results on long lasting effects of IM were reproduced in both experiments. Moreover, to study circadian variation, in Exp. 2 we examined the effects of IM injected in the morning and in the evening hours and reproduced the most results independently on the injection time with two exceptions related to the effect on plasma corticosterone levels and on the small intestinal injury. Because of higher basal plasma corticosterone levels in the evening hours in control vehicle treated rats (normal circadian rhythm of nocturnal animals) IM-induced elevation in plasma corticosterone levels was significant only during the morning hours. The intestinal lesions, as we demonstrated for the first time, were smaller in rats treated with IM in the evening hours. This confirms previous conclusion that the circadian time of application of the ulcerogenic stimulus must be considered as an important experimental factor (Savran et al. 1997). However, previously the development of IM-induced gastric injury was studied at an earlier time point, which was not evaluated in our present experiment. Moreover, our results support also the gastroprotective role of glucocorticoids as more severe intestinal lesion detected at the nadir of corticosterone level (Filaretova 2013).

According to the results, the long lasting effects of IM treatment obtained were preceded by early somatic and behavioral changes. Moreover, somatic changes were found even during $24 \mathrm{~h}$ preliminary fasting of rats in the telemetric study (Fig. 1). Fasting is a required component of gastric ulcerogenic models (Kato et al. 2009; Rios et al. 2010; Zelena and Filaretova 2010). Beside GI 
components our previous results have already shown that a general reduction in blood glucose induced by IM injection (Filaretova et al. 2002) is a key element in the pathogenesis of the injury triggering an increase in gastric motility (Laine et al. 2008; Hermann et al. 2014). The results of $24 \mathrm{~h}$ telemetric recordings show circadian variation of heart rate, core body temperature, and locomotion with higher levels during the dark phase and lower levels during the light phase in control rats. The data are in agreement with other studies including our previous one (Filaretova et al. 2011) and with normal circadian rhythms of nocturnal animals that are more active during the dark phase of the day. We further demonstrated for the first time that fasting itself resulted in significant changes in telemetrically recorded parameters with the most prominent changes in heart rate. Fasting caused a significant reduction in heart rate during both the light and dark phases and a decrease in the body temperature only during the light phase. On the contrary, fasting induced significant increase in locomotion during the first hours of the dark phase which may be explained by a search for food. Taken together, fasting-induced general somatic changes observed in the present study can make the rats more vulnerable to ulcerogenic stimuli.

Further data obtained demonstrate in general how sensitive rats are during various steps of experimental conditions: significant and long lasting increase in heart rate, core body temperature, and locomotion in response to s.c. saline injection as well as refeeding were detected (Fig. 2). Nevertheless, IM injection induced significant changes in heart rate and core body temperature even when compared to saline injection. Our previous results showed a long-term disruption of circadian rhythmicity following IM treatment (Filaretova et al. 2011), which could be anticipated upon present data (assuming that all studied parameters remained low as shown in Fig. 3), however this time we were concentrated on the first $24 \mathrm{~h}$ of ulcer formation and healing. The earliest and strongest effect of IM occurred on body temperature detectable already $2 \mathrm{~h}$ after the IM injection, intensified with time and remained strong even during the light phase, till the end of observation. We did not find any effect of IM injection on heart rate during the development of gastric erosion but it was well visible later, approximately $3 \mathrm{~h}$ after refeeding during the dark phase and partly also during the light phase. These early somatic changes could prolong the recovery, thereby contributing to the development of long term aversive effects of ulcerogen IM injection.
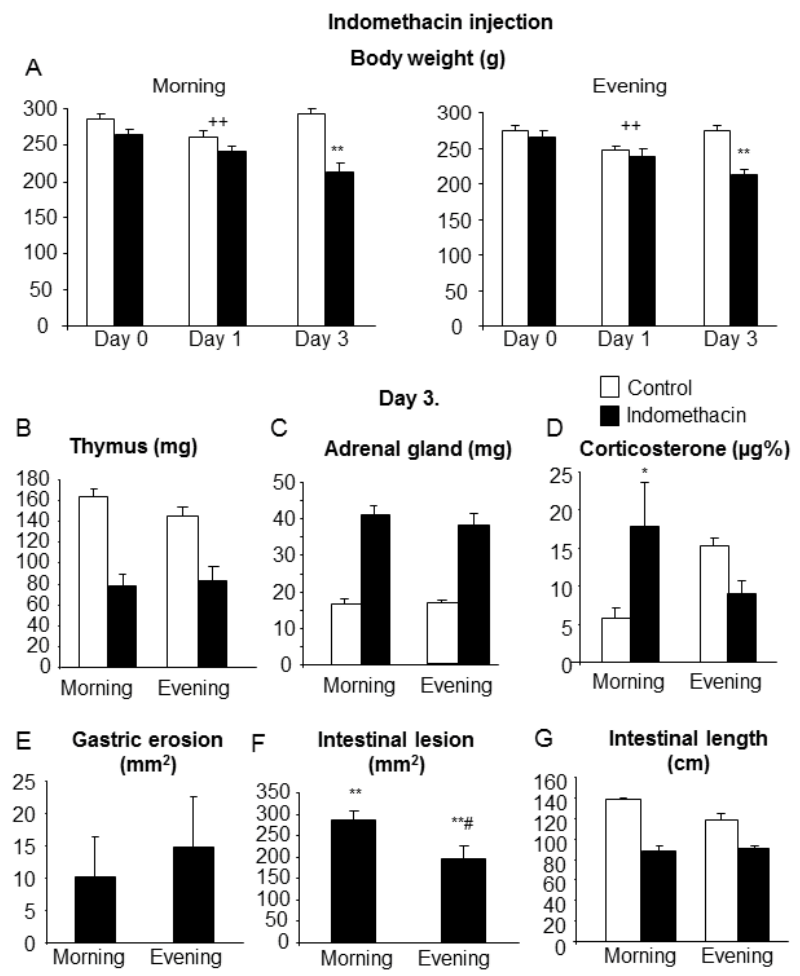

Fig. 4. Difference in morning or evening treated/sampled animals. Indomethacin treatment ( $35 \mathrm{mg} / \mathrm{kg}$ s.c. in fasted rats) induced a significant reduction in the body (A) and thymus (B) weight and an elevation in adrenal weight $(C)$ during 3 days examination period without any day effect. Plasma corticosterone levels (D) were higher in the evening and indomethacin induced elevation during the morning hours only. Areas of gastric (E) as well as intestinal (F) lesion were significantly larger after indomethacin treatment, because we had no GI injury $\left(0 \mathrm{~mm}^{2}\right)$ in saline-treated rats (without IM). On the contrary, the length of the intestine (G) was significantly lower compared to vehicle treated animals. The intestinal lesions were smaller in evening treated/sampled animals without day effect on other parameters. $n=5 ;++p<0.01$ main time effect compared to day 0 ; \# $p<0.05$ vs. morning treatment; ${ }^{*} p<0.05$, ${ }^{* *} \mathrm{p}<0.01$ vs. vehicle injection.

Despite our expectation that IM-induced ulceration will be accompanied by enhanced anxiety-like behavior on EPM, we were unable to detect a clear reduction of the main measured parameters (open arm time and open/total entries). On the other hand, the IM-induced significant reduction of locomotion is also detectable after various stressor exposures (Carli et al. 1989; Klenerova et al. 2011) and can be a sign of anxiety-prone personality (Geerse et al. 2006). The ethologically relevant parameter, high self grooming 
is an additional sign of anxiety (Bagdy et al. 2001; Lee et al. 2014). Its slightly higher level after IM treatment further suggests a tendency for more anxious phenotype. At the same time, reduced locomotion could be a prominent symptom among so-called sickness behaviors (Matsuoka and Narumiya 2008). Because in our hands it is not accompanied by fever (on the contrary, with reduced temperature), it seems much more likely that IM-induced reduced locomotion is a sign of anxiety-like behavior rather than a pure reflection of a disease state. Beside the behavioral parameters IM treatment reduced also the autonomic responses (temperature elevation) due to stressor (EPM) exposure. According to our knowledge beside a previous report from our group on enhanced heart rate and locomotion during the EPM test (Haller et al. 2004) there is no report in the literature on changes of autonomic parameters during anxiety tests. The reduced reactivity detectable in IM-treated rats sug- gest a disturbed adaptation to environmental stimuli (Roth et al. 2012), indicating an enhanced vulnerability to new challenges.

These results suggest that fasting itself may induce somatic changes, which can make the animals more vulnerable to ulcerogen stimuli. Development of IMinduced gastrointestinal lesions goes parallel with disturbances of heart rate, core body temperature, and chronic stress-like somatic changes as well as anxietylike behavior. We should be more aware of the existence of the brain-gut axis and study changes in the whole body rather than focusing on a specific organ.

\section{Acknowledgement}

This study was supported by an OTKA grant (K101645), Programs of Presidium RAS 7P and 5P, grants of RFBR-13-04-01680-a and Russian Scientific Foundation N14-15-00790 (Exp.2).

\section{References}

Bagdy G, Graf M, Anheuer ZE, Modos EA, Kantor S: Anxiety-like effects induced by acute fluoxetine, sertraline or m-CPP treatment are reversed by pretreatment with the 5-HT2C receptor antagonist SB-242084 but not the 5-HT1 A receptor antagonist WAY-100635. Int J Neuropsychopharmacol 4, 399-408, 2001. http://dx.doi.org/10.1017/S1461145701002632

Bjarnason I, Scarpignato C, Takeuchi K, Rainsford KD: Determinants of the short-term gastric damage caused by NSAIDs in man. Aliment Pharmacol Ther 26, 95-106, 2007. http://dx.doi.org/10.1111/j.1365-2036.2007.03348.x

Borre YE, Moloney RD, Clarke G, Dinan TG, Cryan JF: The impact of microbiota on brain and behavior: mechanisms \& therapeutic potential. Adv Exp Med Biol 817, 373-403, 2014. http://dx.doi.org/10.1007/978-1-4939-0897-4 17

Brzozowski T: Nonsteroidal anti-inflammatory drug-induced experimental gastropathy: is gastric acid the major trigger? Clin Exp Pharmacol Physiol 37, 651-653, 2010. http://dx.doi.org/10.1111/j.1440-1681.2010.05392.x

Carli M, Prontera C, Samanin R: Effect of 5-HT1A agonists on stress-induced deficit in open field locomotor activity of rats: evidence that this model identifies anxiolytic-like activity. Neuropharmacology 28, 471-476, 1989. http:// dx.doi.org/10.1016/0028-3908(89)90081-6

Dekanski JB, Macdonald A, Sacra P: Effects of fasting, stress and drugs on gastric glycoprotein synthesis in the rat. Br J Pharmacol 55, 387-392, 1975. http://dx.doi.org/10.1111/j.1476-5381.1975.tb06942.x

Farmer AD, Randall HA, Aziz Q: It's a gut feeling: How the gut microbiota affects the state of mind. J Physiol 592, 29812988, 2014.

Filaretova LP, Filaretov AA, Makara GB: Corticosterone increase inhibits stress-induced gastric erosions in rats. Am J Physiol 274, G1024-1030, 1998.

Filaretova L, Podvigina T, Bagaeva T, Makara G: Gastroprotective action of glucocorticoids during the formation and the healing of indomethacin-induced gastric erosions in rats. J Physiol Paris 95, 201-208, 2001. http://dx.doi. org/10.1016/S0928-4257(01)00026-2

Filaretova L, Tanaka A, Miyazawa T, Kato S, Takeuchi K: Mechanisms by which endogenous glucocorticoid protects against indomethacin-induced gastric injury in rats. Am J Physiol Gastrointest Liver Physiol 283, G1082-1089, 2002.

Filaretova LP, Podvigina TT, Bobryshev PY, Bagaeva TR, Tanaka A, Takeuchi K: Hypothalamic-pituitary-adrenocortical axis: the hidden gold in gastric mucosal homeostasis. Inflammopharmacology 14, 207-213, 2006. http://dx.doi. org/10.1007/s10787-006-1544-2

Filaretova LP, Bagaeva TR, Amagase K, Takeuchi K: Contribution of glucocorticoids to protective influence of preconditioning mild stress against stress-induced gastric erosions. Ann N Y Acad Sci 1148, 209-212, 2008. http://dx.doi. org/10.1196/annals.1410.005 
Filaretova L, Morozova O, Bagaeva T, Podvigina T: From gastroprotective to proulcerogenic action of glucocorticoids on the gastric mucosa. J Physiol Pharmacol 60 Suppl 7, 79-86, 2009.

Filaretova L: Glucocorticoids are gastroprotective under physiological conditions Therapeutic Advances in Chronic Disease 2, 333-342, 2011.

Filaretova LP, Bagaeva TR, Morozova OY, Zelena D: The healing of NSAID-induced gastric lesion may be followed by small intestinal and cardiovascular side effects. J Physiol Pharmacol 62, 619-625, 2011.

Filaretova L: Gastroprotective role of glucocorticoids during NSAID-induced gastropathy. Curr Pharm Des 19, 29-33, 2013.

Filaretova L, Morozova O, Laszlo F, Morschl E, Zelena D: Does chronic stress enhance the risk of diseases? Endocr Regul 47, 177-188, 2013. http://dx.doi.org/10.4149/endo_2013_04_177

Filaretova L, Podvigina T, Bagaeva T, Morozova O: From gastroprotective to ulcerogenic effects of glucocorticoids: role of long-term glucocorticoid action. Curr Pharm Des 20, 1045-1050, 2014. http://dx.doi.org/10.2174/13816128 113199990419

Foster JA, McVey Neufeld KA: Gut-brain axis: how the microbiome influences anxiety and depression. Trends Neurosci 36, 305-312, 2013. http://dx.doi.org/10.1016/j.tins.2013.01.005

Geerse GJ, van Gurp LC, Wiegant VM, Stam R: Individual reactivity to the open-field predicts the expression of stress-induced behavioural and somatic pain sensitisation. Behav Brain Res 174, 112-118, 2006. http://dx.doi. org/10.1016/j.bbr.2006.07.010

Haller J, Halasz J, Mikics E, Kruk MR: Chronic glucocorticoid deficiency-induced abnormal aggression, autonomic hypoarousal, and social deficit in rats. J Neuroendocrinol 16, 550-557, 2004. http://dx.doi.org/10.1111/j.13652826.2004.01201.x

Hawkey CJ: Nonsteroidal anti-inflammatory drug gastropathy. Gastroenterology 119, 521-535, 2000. http://dx.doi. org/10.1053/gast.2000.9561

Hermann GE, Viard E, Rogers RC: Hindbrain glucoprivation effects on gastric vagal reflex circuits and gastric motility in the rat are suppressed by the astrocyte inhibitor fluorocitrate. J Neurosci 34, 10488-10496, 2014. http://dx.doi. org/10.1523/JNEUROSCI.1406-14.2014

Hunt RH, Yuan Y: Acid-NSAID/Aspirin Interaction in Peptic Ulcer Disease. Dig Dis 29, 465-468, 2011. http://dx.doi. org/10.1159/000332211

Imaeda H, Fujimoto T, Takahashi K, Kasumi E, Fujiyama Y, Andoh A: Terminal-restriction fragment length polymorphism (T-RFLP) analysis for changes in the gut microbiota profiles of indomethacin- and rebamipide-treated mice. Digestion 86, 250-257, 2012. http://dx.doi.org/10.1159/000341508

Juby A, Davis P: Psychological profiles of patients with upper gastrointestinal symptomatology induced by non-steroidal anti-inflammatory drugs. Ann Rheum Dis 50, 211-213, 1991. http://dx.doi.org/10.1136/ard.50.4.211

Kamei K, Kubo Y, Kato N, Hatazawa R, Amagase K, Takeuchi K: Prophylactic effect of irsogladine maleate against indomethacin-induced small intestinal lesions in rats. Dig Dis Sci 53, 2657-2666, 2008. http://dx.doi.org/10.1007/ $\underline{\text { s10620-008-0199-9 }}$

Karadi O, Nagy Z, Bodis B, Mozsik G: Atropine-induced gastrointestinal cytoprotection dependences to the intact of vagal nerve against indomethacin-induced gastrointestinal mucosal and microvascular damage in rats. J Physiol Paris 95, 29-33, 2001. http://dx.doi.org/10.1016/S0928-4257(01)00006-7

Kato S, Ohkawa F, Ito Y, Amagase K, Takeuchi K: Role of endothelial nitric oxide synthase in aggravation of indomethacininduced gastric damage in adjuvant arthritic rats. J Physiol Pharmacol 60, 147-155, 2009.

Kawahara R, Yasuda M, Hashimura H, Amagase K, Kato S, Takeuchi K: Activation of alpha7 nicotinic acetylcholine receptors ameliorates indomethacin-induced small intestinal ulceration in mice. Eur J Pharmacol 650, 411-417, 2011. http://dx.doi.org/10.1016/j.ejphar.2010.10.031

Klarer M, Arnold M, Gunther L, Winter C, Langhans W, Meyer U: Gut vagal afferents differentially modulate innate anxiety and learned fear. J Neurosci 34, 7067-7076, 2014. http://dx.doi.org/10.1523/JNEUROSCI.0252-14.2014

Klenerova V, Flegel M, Skopek P, Sida P, Hynie S: Galanin modulating effect on restraint stress-induced short- and long-term behavioral changes in Wistar rats. Neurosci Lett 502, 147-151, 2011. http://dx.doi.org/10.1016/j. neulet.2011.06.051

Laine L: The gastrointestinal effects of nonselective NSAIDs and COX-2-selective inhibitors. Semin Arthritis Rheum 32 , 25-32, 2002. http://dx.doi.org/10.1053/sarh.2002.37217

Laine L, Takeuchi K, Tarnawski A: Gastric mucosal defense and cytoprotection: bench to bedside. Gastroenterology 135 , 41-60, 2008. http://dx.doi.org/10.1053/j.gastro.2008.05.030

Lee JH, Kim JY, Jahng JW: Highly Palatable Food during Adolescence Improves Anxiety-Like Behaviors and HypothalamicPituitary-Adrenal Axis Dysfunction in Rats that Experienced Neonatal Maternal Separation. Endocrinol Metab (Seoul) 29, 169-178, 2014. http://dx.doi.org/10.3803/EnM.2014.29.2.169 
Magni G, Di Mario F, Aggio L, Borgherini G: Psychosomatic factors and peptic ulcer disease. Hepatogastroenterology 33, 131-137, 1986.

Magni G, Di Mario F, Trinciarelli G, Borgherini G, Silvestri A: Personality factors in chronic gastric and duodenal ulcers: a controlled study. Gastroenterol Clin Biol 12, 926-930, 1988.

Matsuoka T, Narumiya S: The roles of prostanoids in infection and sickness behaviors. J Infect Chemother 14, 270-278, 2008. http://dx.doi.org/10.1007/s10156-008-0622-3

Mikics E, Barsy B, Barsvari B, Haller J: Behavioral specificity of non-genomic glucocorticoid effects in rats: effects on risk assessment in the elevated plus-maze and the open-field. Horm Behav 48, 152-162, 2005. http://dx.doi. org/10.1016/j.yhbeh.2005.02.002

Ng SC, Chan FK: NSAID-induced gastrointestinal and cardiovascular injury. Curr Opin Gastroenterol 26, 611-617, 2010. http://dx.doi.org/10.1097/MOG.0b013e32833e91eb

Overmier JB, Murison R: Anxiety and helplessness in the face of stress predisposes, precipitates, and sustains gastric ulceration. Behav Brain Res 110, 161-174, 2000. http://dx.doi.org/10.1016/S0166-4328(99)00193-X

Rios ER, Rocha NF, Venancio ET, Moura BA, Feitosa ML, Cerqueira GS, Soares PM, Woods DJ, de Sousa FC, Leal LK, Fonteles MM: Mechanisms involved in the gastroprotective activity of esculin on acute gastric lesions in mice. Chem Biol Interact 188, 246-254, 2010. http://dx.doi.org/10.1016/j.cbi.2010.07.020

Roth MK, Bingham B, Shah A, Joshi A, Frazer A, Strong R, Morilak DA: Effects of chronic plus acute prolonged stress on measures of coping style, anxiety, and evoked HPA-axis reactivity. Neuropharmacology 63, 1118-1126, 2012. http://dx.doi.org/10.1016/j.neuropharm.2012.07.034

Savran B, Gorgun CZ, Zengil H: Circadian reactivity rhythm of rat gastric mucosa to restraint-cold stress and indomethacin: temporal variation in the protective effect of iloprost. Chronobiol Int 14, 575-583, 1997. http://dx.doi. org/10.3109/07420529709001448

Sostres C, Gargallo CJ, Lanas A: Nonsteroidal anti-inflammatory drugs and upper and lower gastrointestinal mucosal damage. Arthritis Res Ther 15 Suppl 3, S3, 2013. http://dx.doi.org/10.1186/ar4175

Targownik LE, Metge CJ, Leung S, Chateau DG: The relative efficacies of gastroprotective strategies in chronic users of nonsteroidal anti-inflammatory drugs. Gastroenterology 134, 937-944, 2008. http://dx.doi.org/10.1053/j. gastro.2008.01.010

Teran-Ventura E, Aguilera M, Vergara P, Martinez V: Specific changes of gut commensal microbiota and TLRs during indomethacin-induced acute intestinal inflammation in rats. J Crohns Colitis 8, 1043-1054, 2014. http://dx.doi. org/10.1016/j.crohns.2014.02.001

Tillisch K: The effects of gut microbiota on CNS function in humans. Gut Microbes 5, 404-410, 2014. http://dx.doi. org/10.4161/gmic. 29232

Vane JR: Inhibition of prostaglandin synthesis as a mechanism of action for aspirin-like drugs. Nat New Biol 231, 232235, 1971. http://dx.doi.org/10.1038/newbio231232a0

Wallace JL: NSAID gastropathy and enteropathy: distinct pathogenesis likely necessitates distinct prevention strategies. Br J Pharmacol 165, 67-74, 2012. http://dx.doi.org/10.1111/j.1476-5381.2011.01509.x

Wallace JL, Vong L: NSAID-induced gastrointestinal damage and the design of GI-sparing NSAIDs. Curr Opin Investig Drugs 9, 1151-1156, 2008.

Yoda Y, Amagase K, Kato S, Tokioka S, Murano M, Kakimoto K, Nishio H, Umegaki E, Takeuchi K, Higuchi K: Prevention by lansoprazole, a proton pump inhibitor, of indomethacin -induced small intestinal ulceration in rats through induction of heme oxygenase-1. J Physiol Pharmacol 61, 287-294, 2010.

Zelena D, Filaretova L: Age-dependent role of vasopressin in susceptibility of gastric mucosa to indomethacin-induced injury. Regul Pept 161, 15-21, 2010. http://dx.doi.org/10.1016/j.regpep.2009.12.015 